\title{
Initial Learnings as the OHAfrica Team Commences Its Work at an HIV Clinic in Lesotho
}

\author{
n December, the OHAfrica Lesotho Initiative, a partnership \\ between the Ontario Hospital Association, the Change \\ Foundation and the Government of Lesotho (Ministry of \\ Health and Social Welfare), placed the first team of healthcare \\ professionals at an HIV clinic in Lesotho to work with local \\ counterparts to develop a sustainable strategy for the provi- \\ sion of HIV/AIDS care, including antiretroviral therapy. \\ After the requisite tour of the HIV clinic and hospital, and a \\ welcome lunch on the team's first day in Leribe, Dr. Lekena, \\ the clinic director, asked "Shall we begin?" The first patient \\ seen by the OHAfrica team had come for antiretrovirals (ARVs) \\ with two sets of health records (patients carry their health \\ records in a small book in Lesotho). One book was for her \\ tuberculosis (TB) and the other for HIV. As is often the case, \\ patients will remove pages, borrow another's or carry two
}

least 400 Basotho have been registered at the clinic and seen by a physician. As of January 21st, 115 patients were on ARVs and new patients are now being put on therapy at a rate of 20 per week. Many more have started treatment for opportunistic infections like TB, Pneumocystis carinii pneumonia (PCP) and candidiasis.

However, many people arriving at Tšepong are in the last stage of disease, and often past the point at which ARVs could be most effective. The median CD4 count for patients seen is 108 and almost one-third have counts less than 50 . (Normal ranges from 500 to over 1,000). Approximately threequarters of the 2,000 people tested at the clinic during the month of December were positive. With visible signs of illness, they have waited too long to get tested in a country where it is estimated that three in ten people are HIV positive.

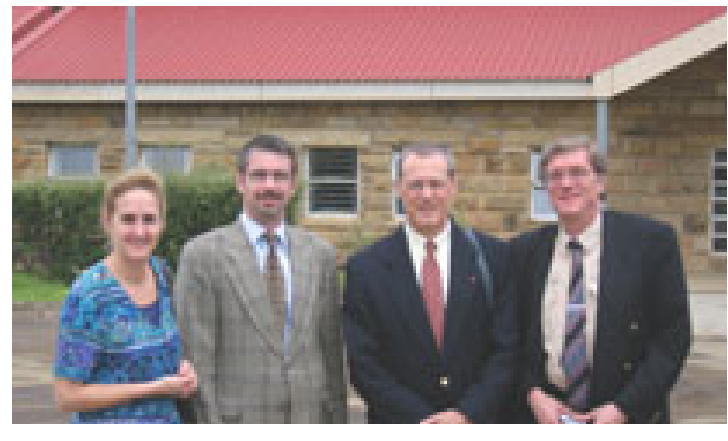

The first OHAfrica Lesotho Team, from left: Dale McMurchy, Russell Armstrong, Dr. Robert Lesotho just prior to World AIDS Day 2004. Birnbaum, Dr. Phil Berger. This team arrived in

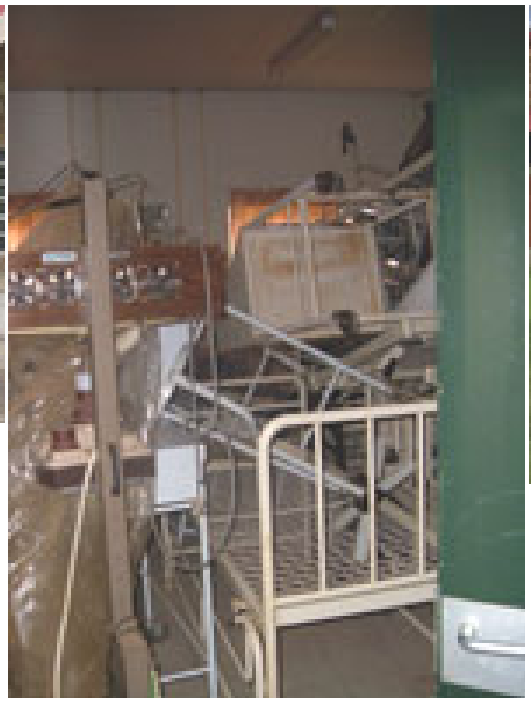

books to hide their HIV status in a place where the stigma carries a heavy weight. Luckily, on that day this patient, a teacher, had brought both. She had been on ARVs in the past. Purchased from a private clinic, she had had to go off the drugs when she could no longer afford them. Now, she was on TB treatment. Had the team been unaware of this, she would have been prescribed the ARVs she had been on previously, medication contra indicated with her current TB treatment. And so it began, with so many important lessons learned by the OHAfrica team from their very first patient.

Despite the lack of very basic equipment and supplies, blood drawn only two mornings a week, interruptions in the supply of ARVs and other important medications and no paediatric ARVs, the clinic is making progress. Since the OHAfrica team started working at Tšepong clinic (Place of Hope), at

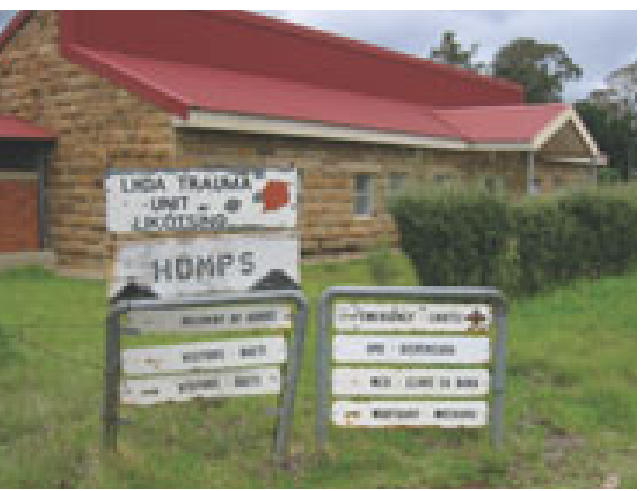

TOP: ... clinic is a renovated ward of the hospital unfortunately located next to the mortuary (although that proximity has sadly also proved opportune).

LEFT: A storage closet at the clinic is full but not necessarily the items needed for patient care: drugs, IVs, gauze.

There are significant barriers to getting testing and effective treatment in Lesotho. Many must walk great distances and then travel several hours by bus to reach the clinic. Some, too ill to travel alone, must be accompanied. The cost of the transport to and from the clinic and the charge for care, totalling about $\$ 10$, is prohibitive for many Basotho. Moreover, commencement of treatment and follow up entails several clinic visits. As well, stigma remains an issue in a place where many AIDS deaths are attributed to bewitchment, women are not in a position to say no or insist on condom use and misinformation is widespread.

Malnutrition may be the greatest impediment to effective treatment for HIV. Hunger increases the progress of disease, 
undermines the body's ability to respond to treatment and may in fact lead to increased toxicity of the drugs. Many of the patients seen at Tšepong are malnourished and nutritional supplements are as yet unavailable.

The clinic itself is a renovated ward of the hospital (each ward is a separate building) unfortunately located next to the mortuary (although that proximity has sadly also proved opportune). Fulltime Basotho staff at the clinic includes five counsellors, a pharmacist and Dr. Lekena. The counsellors are committed and energetic. In addition to counselling and testing approximately 100 people a day among them, they also fill the roles of receptionists, clerks and nurses among many others. They greet the patients, file test results and take patient histories. They also keep the Canadians up to date with the goings on throughout the hospital. From a room the size of a closet, the pharmacist orders and manages her supply of drugs, dispenses ARVs and other drugs, and provides detailed counselling to several patients a day on the importance of adherence to their therapy and the signs and symptoms of adverse events associated with their medications, some of which in and of themselves can be quite serious.

In addition to her clinical skills, Dr. Lekena provides leadership and support to the clinic team. Her insight and technical guidance have been invaluable to the OHAfrica team during its set-up period in Lesotho. In an erudite and tactful way, she has taught the team how to provide healthcare in a resource poor environment, how to diagnose and treat illnesses like TB and kwashiorkor (protein-deficient malnutrition) that Canadian doctors rarely see, how to read patients by their dress and demeanour, and how to interpret the way patients understand and describe illness.

The OHAfrica team has integrated itself remarkably quickly into the clinic, and has developed a collegial and respectful working relationship with the clinic team. Outside the clinic, education sessions for doctors and nursing sisters have already improved the care of AIDS patients at the hospital. For example, local doctors are now able to diagnose and treat PCP.

Much learning has gone both ways in the first two months in which the OHAfrica team has been in Lesotho, an important dynamic for the success of any such initiative. After a few weeks in Lesotho, one team member mused, "I have learned more in the last two weeks, than in the past 20 years."

Dale McMurchy is the Manager of the OHAfrica Lesotho Initiative. For more information about the OHAfrica Lesotho Initiative, please visit the website at www.OHAfrica.ca, or if you are interested in supporting the initiative, please send an e-mail to ohafrica@oha.com.
The Canadian Nurses

Association has launched

a redeveloped website that

will give users quick access

to reliable information about

the nursing profession and

Fast,

health care.

\section{Reliable,}

\section{Professional}

In consultation with nurses and stakeholders from across Canada, CNA has developed a site that is:

- dynamic

- well organized

- informative

- progressive

- credible 